\title{
ENTRE LÍMITE Y FRONTERA: EL RECORRIDO HISTÓRICO DE LA INTEGRACIÓN ENTRE EL NORTE DE LA PATAGONIA ARGENTINA Y EL SUR DE CHILE
}

\author{
Por \\ Susana Bandieri*
}

\begin{abstract}
RESUMEN
El propósito de este artículo es dar a conocer los antecedentes históricos de las relaciones económicas, sociales y culturales vigentes entre el norte de la Patagonia argentina y el sur de Chile desde la etapa de dominación indígena. Avanzado el siglo $\mathrm{xX}$, importantes medidas arancelarias tomadas por ambos Estados nacionales, como producto de la necesidad de asegurar sus propios mercados internos, provocarían la afirmación de los controles de tránsito a través de Los Andes y el fin de la integración, transformando definitivamente un área fronteriza en área limítrofe. Se analizan también proyectos sucesivos más recientes como la construcción de un ferrocarril trasandino. Éste y otros proyectos se recuperan hoy en el marco de la discusión por la incorporación de Chile al Mercosur. Argentina y Chile tienen actualmente, a causa de la globalización mundial, sobrados motivos para discutir el tema de la integración como una forma de sobrevivencia posible para los países del cono sur de América, cuya condición actual de desintegración y aislamiento constituye un dato más de la realidad vigente en el conjunto latinoamericano.
\end{abstract}

\begin{abstract}
The main objective of this article is to provide the reader with information about historic facts on the economic, social and cultural relations effective between the north of the Argentina Patagonia and the south of Chile from the time of the native domination. Later in the $20^{\circ}$ century, important customs measures were taken by both national States, as a result of the need to insure their own internal markets, they would provoke the affirmation of the traffic controls through Los Andes and the end of the integration, utterly transforming a border area into a neighbouring area. Also, more recent successive proyects are analyzed like the construction of the "trasandino" railroad. This and other projects are rescued today in the discussion by the incorporation of Chile in Mercosur. Argentina and Chile to this day have, because of the word globalization, more than enough reasons to discuse the topic about the integration as a form of possible survival for countries such as southern America, whose actual condition of disintegration and exclusion constitutes one more data about the actual reality in Latin America.
\end{abstract}

* Licenciada en historia; investigadora del Consejo Nacional de Investigaciones Científicas y Técnicas (Conicet); profesora titular de historia argentina y regional en la Universidad Nacional del Comahué, Neuquén, Argentina y directora del Centro de Estudios de Historia Regional y Relaciones Fronterizas (Cehir). 


\section{A MANERA DE PRESENTACIÓN}

Las provincias de Neuquén y Río Negro, en el norte de la Patagonia argentina, y las provincias de Maule, Linares, Nuble, Concepción, Bío Bío, Arauco, Malleco, Cautín, Valdivia, Osomo y Llanquihue, en el sur de Chile, son zonas limítrofes entre sí y alejadas de las capitales políticas y económicas de sus respectivos espacios nacionales: Buenos Aires y Santiago, Esta característica greográfica y múltiples condicionantes históricos, posibilitaron por largo tiempo su integración en un espacio fronterizo socialmente compartido. A lo largo del siglo $\mathrm{XX}$, sin embargo, la imposición de sucesivas estrategias territoriales determinaron su definitivo aislamiento e incorporación a los respectivos espacios nacionales.

En las actuales condiciones mundiales, las nuevas estrategias políticas y un importante número de pasos fronterizos que comunican naturalmente a la region -once de ellos formalmente habilitados-, abren potenciales formas de integración generando una serie de expectativas en el orden local. Se impone, entonces, una aproximación histórica al problema.

Entre 1879 y 1885 , los ejércitos de ambos países lograron someter a las poblaciones indígenas de la región, cortando la tradicional comunicación entre la Araucanía y las Pampas. El éxito de las operaciones militares permitió consolidar unidades territoriales nacionales, "interrumpidas" hasta allí por la existencia de territorios indígenas. Expropiados éstos a sus dueños originarios, se impuso a la región una frontera: la cordillera de los Andes, como límite geográfico y político. ${ }^{1} \mathrm{La}$ investigación sobre historia regional que venimos desarrollando, ba permitido demostrar, sin embargo, que el funcionamiento socioeconómico de las áreas fronterizas continuó actuando por encima de la imposición de tales límites, al menos durante todo el siglo XIX y primeras décadas del XX.

La red de intercambios económicos y demográficos entre ambos lados de la cordillera, conformada en el transcurso de varios siglos de contactos, se vio asimismo favorecida en los inicios del siglo actual por el predominio de los acuerdos entre los dos países, donde primó la fórmula de "cordillera libre". Posteriores etapas de consolidacion de las respectivas situaciones nacionales llevaron a la aplicación de restricciones arancelarias y no arancelarias que, unidas a la carencia en la región de una infraestructura moderna y adecuada en comunicaciones fronterizas, cortaron de manera

\footnotetext{
En este sentido, debe distinguirse necesariamente entre límite y frontera. En tanto el primero indica una línea de demarcación orientada "hacia adentro", porque define un límite territorial sobre el que se ejerce el derecho inherente a un Estado-nación, el segundo refiere una orientación "bacia afuera", pues es una franja-área de contacto sobre la cual los Estados ejercen compromisos geopolíticos (Martín y Taylor, 1994, cit. en Laurín, 1994).
} 
prácticamente definitiva el tradicional intercambio comercial en un proceso gradual iniciado en la década de 1920, profundizado alrededor de los años treinta y concluido hacia mediados de la década de 1940. De hecho, puede decirse que recién al tomar formas concretas el modelo sustitutivo de importaciones y definirse estrategias territoriales más ceradas, de corte nacionalista, se tomo particularmente importante la consolidación de un mercado interno, y por ende, la afirmación de las respectivas fronteras nacionales.

En los últimos años, por efecto directo de los cambios en el sistema mundial, la cuestión de la integración entre los países del cono sur de América volvió a ser tema de interés de los distintos gobiemos nacionales, confirmando aquello de que son las políticas estatales las que vuelven relevantes las cuestiones fronterizas.

Hoy, el fenómeno de la globalización mundial exige nuevas definiciones territoriales que garanticen a los centros involucrados una adecuada circulación de bienes y personas. En el caso que nos ocupa, la década de los noventa mostraría significativos cambios.

La constitución de la Comisión de Complementación Económica entre los representantes de las cancillerias de Chile y Argentina, permitió avizorar un avance más concreto hacia la integración comercial de ambos países y, por extensión, de la región en estudio. Más recientemente, en junio de 1996, se produjo la firma de un acuerdo de libre comercio entre Chile y los países del Mercosur, integrado por Argentina, Brasil, Paraguay y Uruguay. Este acuerdo fue avizorado por las partes como un paso indispensable para completar la integración de los países del cono sur y unificar comercialmente el corredor entre el Atlántico y el Pacífico, ampliando de ese modo la participación de los productos chilenos en el mercado brasileño y acrecentando el comercio de Argentina y Brasil con el sureste asiático a través de los puertos del Pacífico.

A nivel regional, los primeros acuerdos alcanzados en relación con proyectos energéticos - oleoducto y gasoducto a Concepción-, involucran directamente a la provincia del Neuquén y sus recursos naturales.

2 Un interesante análisis de la cuestión realiza el economista Carlos Ábalo (Diario Rio Negro, 19 de mayo de 1996) en el artículo "La difícil relación de Chile con el Mercosur", al referirse al trabajoso acuerdo de libre comercio firmado entre el Mercosur y Chile el 25 de junio de 1996, al que se agregaría Bolivia, por el cual se constituyó una zona de libre comercio para el $100 \%$ de los productos con desgravación progresiva en el término de los próximos años. El máximo plazo previsto es para el comercio de trigo y harina, cuya liberalización absoluta se produciría en 18 años. Asimismo, cabe mencionar la firma de un protocolo de integración física entre ambos países que contempla una significativa inversión en mejoras de caminos y habilitación de pasos fronterizos que permitan la utilización común de los respectivos puertos del Atlántico y el Pacífico. (Diario Río Negro, 20 y 24 de junio de 1996). 
Asimismo, el avance en las conversaciones respecto a la aceptación de la igualdad en el trato fitosanitario permitiría declarar zonas libres a las áreas de exportación - previa cuarentena en origen de los productos frutihortícolas-, otorgando a la zona productora de peras y manzanas del Alto Valle del Río Negro, una interesante posibilidad para la utilización de vías alternativas de exportación a los países del Pacífico. Por otra parte, la más reciente declaración de la provincia del Neuquén como zona libre de aftosa sin vacunación, abre importantes perspectivas para el ganado de cría neuquino, cuyos vacunos podrían colocarse en el mercado trasandino retomando un antiguo vínculo comercial hoy inexistente. También, la producción regional de chivos podría incorporarse rápidamente al nuevo mercado potencial. $^{3}$

Los sucesivos encuentros del Comité de Frontera de la Región de los Lagos, creado en el año 1991, e integrado por representantes oficiales y privados de las provincias argentinas de Río Negro y Neuquén -a las cuales se agrega Chubut $-\mathrm{y}$ de las regiones chilenas vil a XI, que abarcan la zona comprendida entre las localidades de Concepción al norte y Puerto Aysen al sur, como parte de las comisiones binacionales que tratan los temas relativos a la integración, han permitido avanzar en las tratativas respecto a cuestiones comunes del medio fronterizo vinculadas con el comercio, la industria, la producción, la infraestructura, el transporte y el turismo. ${ }^{4}$ También, eI tema de la construcción del tantas veces proyectado ferrocarril trasandino por Neuquén ha vuelto a retomarse, esta vez con la pretensión de abrir un corredor bioceánico entre San Pablo (Brasil) y Talcahuano (Chile) como vía de transporte del Mercosur.

3 Neuquén no tiene aftosa desde el año 1984 , sin embargo, la situación de provincia libre de la enfermedad fue recientemente reconocida por el Senasa (Servicio Nacional de Sanidad Animal), por resolución núm. 211 de mayo de 1996 (Diario Rio Negro, 10 de mayo de 1996). 4 Entre los temas tratados en los distintos encuentros del Comité de Frontera de la Región de los Lagos, que se reúne dos veces por año, figuran: la eliminación de tasas adicionales sobre las lanas que ingresan a Chile; la búsqueda común de fuentes de financiamiento internacionales para posibilitar desarrollos mineros; la interconexión gasífera y petrolifera; un acuerdo de complementación para interconexión eléctrica; la implementación de la tarjeta vecinal fronteriza; acciones comunes en maleria de acuicultura y pesca continental; y la evaluación de los controles fito y zoosanitarios, incluyendo la armonización de procedimientos cuarentenarios y la elaboración de un listado de productos de bajo riesgo de libre circulación entre ambos paises. Se avanza asimismo, en la discusión de cuestiones como el reconocimiento de atenciones médicas en ambos lados de la frontera y los acuerdos para áreas ecológicas. Entre los resultados concretos registrados en los últimos an̉os, se destaca que en 1992, el intercambio comercial alcanzó los 1100 millones de dólares, lo que representó un incremento de $35 \%$ respecto a 1990 (Diario Rio Negro, 11 de noviembre de 1993). La posibilidad de vender hidroenergía a las regiones del sur chileno se discutió tambiến en las reuniones más recientes de mismo organismo ( $x$ Encuentro, 1996), en tanto que la delegación chilena habría dado a conocer nuevos estudios para el tendido del ferrocarril trasandino. En este último encuentro se avanzó también en la discusión de aspectos turísticos y culturales 
De todas maneras, aunque los últimos avances parecen marcar una clara tendencia a retrotraer viejas situaciones de conflicto, las concreciones en la práctica son todavía lentas y relativamente significativas en la región involuctada, salvo en lo referido a la ya finalizada construcción del oleoducto y a los avances en la gestión de la realización del gasoducto trasandino. También se visualizan adelantos en materia de inversiones públicas para el mejoramiento de la red vial de acceso a los pasos fronterizos y al facilitamiento de la circulación de las personas, en relación, sobre todo, con el desarrollo del turismo en la región, aunque esto deberá necesariamente completarse con el establecimiento de un único organismo de control fronterizo.

Ocurre que, tras el difícil tema de la integración entre ambos países, se mueven muchos y variados intereses, públicos y privados, a favor y en contra. Los conflictos limítrofes en el extremo austral del continente americano marcan diferencias políticas difícilmente superables, particularmente si se tiene en cuenta el posible aprovechamiento futuro de la Antártida y de los lechos marinos del área. En la resistencia chilena por integrar el Mercosur, pesan también los efectos seguros de la competencia que generarían en ese país los cereales argentinos, así como la producción frutícola regional, que aumentarian notablemente su mercado potencial frente a la actual ventaja chilena. Cabe recordar, asimismo, el impulso que la internacionalización adquiriera en Chile en los últimos años, tema éste muy vinculado con su postergada aspiración de integrarse al TLC.

Sin embargo, ya sea que se considere el interés chileno por acceder al importante mercado brasileño, como el argentino por conquistar los mercados del Pacífico, ambos países tienen actualmente sobrados motivos para discutir el tema de la integración y redimensionar las hipótesis de conflicto. Es muy posible que sus respectivos gobiemos civiles entiendan hoy, que en el marco de la globalización mundial, y de las exigencias de todo tipo impuestas por los países desarrollados para los productos primarios, una forma de sobrevivencia posible para los países del cono sur de América pasa por la integración, aunque ésta deba tener un alto grado de componentes estratégicos. Por ello, y en el interés de avanzar en la comprensión de los intereses expresados en torno al tema por las estructuras de poder

\footnotetext{
vinculados con la integración de ambas regiones. así como en la concreción de importantes inversiones en rutas que conducen a pasos fronterizos, estableciendo las prioridades regionales en los pasos de Pino Hachado y Puyehue - Cardenal Samoré- (Diario Rio Negro, 7 de mayo de 1996), este último ya pavimentado casi por completo en la actualidad. El norte neuquino reclama, por su parte, un estatus similar para el tradicional paso del área, Pichachén. como vía más corta de comunicación con la vir región.
} 
dentro y fuera de la región misma, parece importante conocer los antecedentes históricos de la cuestión fronteriza en el área que nos ocupa, cuya condición más reciente de desintegración y aislamiento, constituye un dato más de la realidad vigente en el conjunto latinoamericano en los últimos años.

\section{LOS ANTECEDENTES HISTÓRICOS}

Prestigiosos historiadores chilenos fueron los primeros en destacar que la intensa movilización comercial y las relaciones interétnicas eran características propias y distinguibles del funcionamiento fronterizo en la región que nos ocupa. ${ }^{5}$ De esta manera expresaban, en la historiografía trasandina de la década de 1980, la necesidad de replantear los estudios del fenómeno fronterizo en el interés de trascender los análisis tradicionales, exclusivamente centrados en las cuestiones bélicas, y avanzar en la comprensión de la sociedad, la economía y la cultura del área de frontera. Seguramente, su condición de pioneros fue producto de haberse iniciado primero en Chile la consolidación de una situación fronteriza de intensos contactos hispano-indígenas.

De común se reconocen dos etapas bien diferenciadas en la vida fronteriza de la Araucanía chilena (región al sur de los ríos Maule y Bío Bio): una de características estrictamente bélicas entre los años 1563 y 1655 , y otra posterior, de intenso contacto cultural y convivencia pacífica. A partir del siglo Xvir la situación de paz se habría profundizado generando un importante avance de la integración, tanto económica como social, resultado de un activo tráfico comercial y de un elevado grado de mestizaje. Las autoridades españolas en Chile habrian generado, por su parte, distintas vias de adaptación a estas formas integradoras (parlamentos, paces, tratados, incorporación de indios al aparato burocrático-militar, etcétera), preparando de algún modo el avance y conquista definitiva de la Araucanía hacia 1882. Esta especial situación incrementó notablemente la presencia de numerosos mercaderes procedentes de las ciudades chilenas, que periodicamente recorrían la región andina patagónica en busca de ganado y tejidos que conducían al importante mercado de consumo de la región central trasandina.

5 Sergio Villalobos y Jorge Pinto Rodríguez (1985) sostienen que asociar el término "frontera" al concepto de "frontera militar" o "frontera administrativa" sería mantenerse al margen de los progresos en las ciencias sociales, particularmente si se trata de estudiar una frontera tan permeable como la propia. 
La cultura indígena mapuche, por su parte, habría sufrido a lo largo de más de 300 años de vida fronteriza, con mayor o menor grado de inestabilidad social, política y militar, distintas formas de aculturación (mestizaje, incorporación del caballo, etcétera), provocándose asimismo, un acentuado proceso de "araucanización" hacia el oriente cordillerano con consecuencias muy significativas en las parcialidades locales. La magnitud del intercambio con lo hispano habría producido en los grupos indígenas el vuelco a la ganadería en desmedro de la agricultura, siendo también la intensa circulación cordillerana vía de đifusión e incorporación de nuevos elementos culturales como el hierro y la plata, los cereales europeos, el uso del cuero de los animales domésticos, la importancia de la vida pastoril y la complejización de la organización política y militar de los grupos indígenas.

Pero la preocupación de los autores chilenos por la región de la Araucanía se ha limitado, básicamente, a la idea de "frontera" entre españoles e indios, marcando las diversas formas de contactos, bélicos o no, entre una sociedad dominante y una sociedad dominada, donde el predominio de una paz más o menos estable a partir de la segunda mitad del siglo Xvil habria provocado el afianzamiento de las relaciones entre ambas sociedades del norte y sur del Bío Bío. Sin embargo, según vimos, la consolidación de una situación fronteriza de intensos contactos se extendió a través de la cordillera de los Andes. El corrimiento bacia el este del aludido proceso de "araucanización", permitió la ampliación del área de frontera en dirección a las Pampas argentinas, donde las especificidades de los distintos grupos indígenas comenzaron a perderse en función de un intenso mestizaje y una marcada homogeneización cultural, cuya mayor manifestación sería el uso generalizado de la lengua mapuche a partir del mismo siglo XVII,

Ya en el siglo XVIII, y formando parte de esta "sociedad de frontera", los indígenas del Neuquén manejaban una vasta red de caminos y comercio que abarcaba un ancho corredor interregional entre el Río de la Plata y Chile, por el cual circulaban los ganados y bienes diversos del mercado colonial. El norte de la Patagonia argentina era parte sustancial de tal corredor y la isla de Choele Choel, en la actual provincia de Río Negro, era parador obligado de aprovisionamiento y descanso de los animales. Los grupos cordilleranos oficiaban așí de excelentes intermediarios entre los ganados de las Pampas argentinas y la demanda chilena. Al respecto, las autoras Varela y Bizet, que han dedicado un importante esfuerzo a la reconstrucción de los procesos de cambio y transformación operados en los grupos indígenas del área de Neuquén a partir del contacto fronterizo, así como al rol de intermediación que ejercían al controlar los pasos 
cordilleranos, dicen que estos "[...] cazadores y recolectores en la etapa prehispánica, pastores ecuestres y, finalmente, ganaderos y comerciantes, organizaron su patrón economico en función de la sociedad hispano criolla consumidora de sus productos" (Varela y Bizet, 1993:79-80). En efecto, esta sociedad requería importantes cantidades de sal, carnes, cueros y sebos para su propio consumo y para su exportación al centro minero potosino y a otros asentamientos hispanos sobre el Pacífico sur. En esas condiciones, los campos del área antecordillerana del Neuquén resultaban excelentes para el acondicionamiento de los ganados antes de someterlos al esforzado cruce de los Andes.

Aunque la situación de conflicto estaba siempre presente, las relaciones fronterizas siguieron incrementándose durante todo el siglo XVIII, alcanzando niveles muy importantes de intercambio económico y social. Ya en el siglo XIX, los procesos independentistas de ambos países derivaron en mayores presiones territoriales hasta que, sobre la segunda mitad del siglo y mediante sendas campañas militares, se termin $\delta$ por incorporar el espacio indígena a la soberanía de los respectivos Estados nacionales, resolviendo el secular conflicto a favor de los sectores dominantes. ${ }^{6}$

Desde Argentina, la expedición punitiva de 1879 -irónicamente llamada "campaña al desierto"-, tuvo una clara legitimación ideológica en el explicitado propósito de combatir la "barbarie" para asegurar "el progreso y la civilización". Desde esa perspectiva, debe entenderse el término "desierto" con un eminente sentido social más que físico, como sinónimo de "barbarie" o, lo que es lo mismo, "vacío de civilización". Cabe recordar también que este hecho militar debe necesariamente relacionarse con los intereses concretos de los sectores socioeconómicos dominantes, seriamente afectados por los malones indios y el permanente fluir de sus haciendas a Chile. Su definitiva concreción se vio asimismo fortalecida hacia 1880 por la expansión económica del país, hasta ese momento predominantemente pecuaria, que exigía la incorporación de nuevas tierras para aliviar la presión pastoril sobre las llanuras bonaerenses y permitir el incremento de los volúmenes de producción para una correcta respuesta a

6 La siguiente es una buena síntesis del proceso casi simultáneo de ocupación militar del espacio indígena por parte de ambas naciones: "En diciembre de 1882, luego de haber combatido a los guerreros araucanos en Lumaco, Cholchol y Temuco, el ejército chileno logró ocupar los pasos andinos poniendo fin a a las comunicaciones entre la Araucania y las Pampas. Dos años antes, los soldados argentinos, al mando del general Julio A. Roca, realizaron una operación similar, logrando expulsar a las parcial idades rebeldes hacia Chile. Las operaciones de ambos ejércitos - denominadas de pacificación en Chile y conquista del desierto en Argentina-concluyeron militarmente con el "problema indígena", que por más de 300 años había preocupado a las autoridades coloniales y republicanas. (AA.VV. Asociación de Historiadores Chilenos (U.K.), 1982). 
la demanda europea de lanas y carnes. El problema de la "frontera interna" se había convertido, entonces, en la principal traba al modelo de inserción de Argentina en el sistema mundial, vinculado económica y financieramente con las principales potencias del momento, particularmente Inglaterra, cuando éstas no estaban todavía en condiciones de subsidiar su propia producción primaria. Extender y consolidar tal frontera fue, por lo tanto, preocupación esencial de los distintos gobiernos y objeto de políticas diversas a lo largo de todo el siglo XIX. Después de sucesivas campañas militares, la ocupación total de los terntorios patagónicos se completaría, finalmente, hacia el año 1885.

A la expropiación y desafectación de los recursos naturales a las poblaciones indígenas, le siguió la conformación de un marco político e institucional que asegurase el desenvolvimiento de la nueva organización social del espacio, ahora vinculado con las formas capitalistas de producción. El efecto inmediato de tales medidas fue establecer los límites administrativos de los nuevos territorios nacionales (Ley 1532 de 1884) ${ }^{7}$ y considerar a la cordillera de los Andes, al igual que límite político, una barrera aislacionista. En este sentido, el cordón montañoso afirmó su condición de "espalda" de un país cuya orientación se pensaba exclusivamente hacía el Atlántico.

Sin embargo, según se ha dicho, la vinculación con Chile ha sido para los espacios patagónicos cordilleranos una constante desde las etapas más antiguas, ${ }^{8}$ manteniéndose por algunos años las anteriores características de ocupación a pesar de la nueva situación impuesta por la incorporación definitiva de la región al Estado nacional argentino.

7 Las nuevas tierras ganadas al indioen el norte y sur del país, fueron legalmente reconocidas por esta ley como territorios nacionales, y en esa condición mantenidos hasta su definitiva grovincialización sobre mediados de la década de 1950.

La magnitud de esos contactos se hizo evidente cuando, a la llegada de las fuerzas militares, los partes de la campaña del general Roca, transcritos por Manuel Olascoaga, informan de la existencia en el noroeste neuquino de una población cordillerana denorninada Malbarco - hoy Varvarco- con casi 600 habitantes entre indígenas, puesteros y hacendados chilenos que arrendaban terrenos a los caciques comarcanos. Había alli dos estancieros -Price y Méndez Urréjola - sólidamente instalados al momento de producirse la avanzada militar "contra el desierto" (Olascoaga, 1974:148-256; 367-368). Indígenas y chilenos mantenían una particular convivencia en Malbarco, donde los funcionarios del país vecino extendían de hecho su autoridad a través de la presencia de subdelegados civiles, aunque reconociendo la base de poder de los caciques locales al propiciar el arriendo de sus tierras o la firma de tratados teodientes a obtener un trato favorable "[...] con las personas y haciendas de los chilenos residentes al otro lado de la cordillera" (Tratado del lro. de enero de 1872 entre el jefe de operaciones de frontera e intendente de la policía de Arauco, general Basilio Urrutia en representación del gobierno chileno, y embajadotes y representantes de las tribus de Neuquén). 


\section{LOS ESTUDIOS REGIONALES}

Cabe destacar inicialmente, en coincidencia con lo adelantado, que cualquier investigación que se pretenda llevar a cabo en el área norpatagónica circunscribiéndose a los límites políticos y/o geográficos establecidos, corre serios riesgos de no alcanzar nunca niveles explicativos adecuados si no se tiene especialmente en cuenta el funcionamiento del área de frontera y el intenso mundo de relaciones económicas, sociales y culturales con las provincias del sur chileno construido en tomo a ella.

Efectivamente, sucesivos avances en la investigación histórica regional nos han llevado a sostener que el área andina norpatagónica tuvo una posición de marginalidad respecto al modelo de inserción del país en el sistema internacional vigente, con fuerte orientación atlántica, motivando la supervivencia de los contactos socioeconómicos con Chile por encima de la imposición de fronteras políticas. ${ }^{9}$ Por ese mismo motivo, mientras el ganado ovino era desplazado de la llanura pampeana a los territorios patagónicos con litoral atlántico, como consecuencia del auge cerealero y de la importancia de la carne refinada, las áreas cordilleranas estaban también pobladas por una importante cantidad de ganados criollos, particularmente vacunos, destinados a satisfacer la demanda de los centros y puertos chilenos del Pacífico sur.

Cabe al respecto recordar la estructura económica dominante en Chile hacia la segunda mitad del siglo XIX y primeras décadas del XX. La demanda internacional de trigo generó, hacia 1850 , un incremento importante de los cultivos en detrimento de la ganadería, que fue disminuyendo primero en los valles centrales chilenos y después en las regiones del sur del país. Mientras que en los primeros los campos se destinaron al cultivo de viña, maíz, porotos, papas, arvejas, lentejas, garbanzos, árboles frutales y productores de madera industrializable, en la zona de frontera al sur del Bío Bío aumentó considerablemente el área sembrada con trigo cuyo excedente se exportaba a Perú, California, Australia, Uruguay y Argentina -recuérdese que a esa fecha la producción cerealera argentina no alcanzaba todavía a satisfacer las necesidades internas-. Hacia fines del siglo Chile no tenía, en consecuencia, carne suficiente como para cubrir su propio consumo y para sostener la producción y el comercio de tasajo y sebo que desde la dominación hispana había realizado con otros centros

\footnotetext{
9 Al respecto, puede verse de Susana Bandieri, "La cordillera de los Andes en el norte de la Patagonia o la frontera argentino-chilena como espacio social. Un estudio de caso" (1991b:81-108). También de la misma autora "Historia regional y relaciones fronterizas en los Andes meridionales" (1995:49-74).
} 
del Pacífico sur, como Perú y Ecuador, gracias a la permanente provisión de ganados argentinos por parte de los grupos indígenas cordilleranos. Los ahora territorios nacionales del sur argentino, particularmente sus áreas cordilleranas, seguirian siendo proveedores habituales de tal demanda, incrementada también sobre fines del siglo XIX por el cambio productivo de la provincia de Mendoza, que simultáneamente transformaba sus tierras de pastoreo en campos de vides. Deberán recordarse, asimismo, las especiales condiciones que presenta la cordillera de los Andes al sur de la última provincia mencionada, donde sus condiciones: - menores alturas y los numerosos valles transversales-, permiten el tránsito durante la mayor parte del año.

El tema de la circulación de hombres y ganado a través de la cordillera resulta entonces de vital importancia para reconstruir la supervivencia de la compleja red de relaciones económicas y sociales vigentes en el área desde la etapa indígena. Al antiguo rol de intermediación cumplido por estos grupos en las áreas cordilleranas patagónicas, se agrego, a partir de 1880 , una intensa actividad ganadera extensiva basada en la cría de ganado de tipo criollo, de buen peso y escasa calidad, para satisfacer la demanda de consumo del país trasandino y, particularmente, sus industrias del cuero, sebo y salazón de carnes. Las mismas razones permiten explicar la modalidad del asentamiento humano imperante en el área luego de la ocupación militar del espacio, donde las zonas andinas mostraban la mayor cantidad de población, disminuyendo su densidad en tanto más se alejaba de los centros de consumo. Consecuentemente con las características señaladas, buena parte de la población asentada en el área era también de origen chileno, imperando en consecuencias las pautas culturales de ese origen. ${ }^{10}$ Esto no hace más que demostrar la supervivencia de las antiguas formas de organización social vigentes desde la etapa indígena y vinculadas con la actividad ganadera dominante y el destino de la producción regional. Asimismo, permite entender la generalizada práctica de los hacendados chilenos de adquirir tierras de este lado de la cordillera a los efectos de

\footnotetext{
${ }^{10}$ La supervivencia histórica de tales prácticas puede verse claramente reflejada en la descripción que en 1920 hace de Neuquén el inspector de tierras, Ramón Castro "[...] en la zona de precordillera está la mayor parte de la población del terntorio [...] el $80 \%$ de la población adulta es chilena, que tiene un inmenso caríno a su tierra y vive inculcando su tradición, usos y costumbres [...] sus hijos son inscritos en la vecina república. Chilenos son también la mayor parte de los capitales, el comercio y la moneda que circula, especialmente en la parte norte del territorio donde no se conoce otra, a tal punto que cuando la Comisión Inspectora percibió los derechos de pastaje, los pobladores tuvieron que gestionar especialmente el dinero argentino, llegando los bolicheros, que hacían de agencias de cambio, a vender un peso argentino por cinco chilenos [...]" (Informes generales de la Comisión Inspectora de Neuquén, 1921-1922;37-38).
} 
descargar de ganado sus propios campos, inadecuados para el pastoreo extensivo y dedicados básicamente a la agricultura. ${ }^{11}$

Esta situación de contactos fluidos en lo que hace a la comercialización del ganado, parece haberse mantenido con ligeras variantes hasta la década de 1920, en directa relación con la presencia de distintas políticas nacionales respecto al mantenimiento de franquicias comerciales donde la formula de "cordillera libre", particularmente defendida por Argentina, logró imponerse durante lapsos más o menos prolongados, coincidiendo con el periodo de mayor auge de la ganadería regional. Hacia la segunda mitad de esa década, el área andina norpatagónica, tradicional abastecedora de ciudades y puertos chilenos, habría quedado más decididamente separada de su mercado natural por la imposición de medidas arancelarias aplicadas especialmente por Chile al comercio fronterizo, con efectos especialmente evidentes durante la crisis internacional de los años treinta, y definitivamente aislada del mismo en la década de 1940, después de la segunda guerra mundial. Los altos aranceles aplicados al comercio entre ambos países, son síntomas claros de la ya explicitada intención de los gobiernos nacionales por asegurar sus respectivos mercados internos para la producción industrial por sustitución de importaciones, coincidentemente con la crisis sufrida por el modelo agroexportador entre los mismos años, ${ }^{12}$ Esto habría provocado una serie de consecuencias regionales tales como una importante crisis en la actividad ganadera del área andina de Neuquén, el despoblamiento de algunas zonas rurales y la redistribución de roles de los actores sociales involucrados, cuestiones todas particularmente sentidas en el noroeste del territorio donde las condiciones de pobreza eran más marcadas y las alternativas posibles más limitadas.

Fue así como las unidades productoras más pequeñas del área rural andina norpatagónica, vinculadas con la práctica de una ganadería trashumante, habituadas a comercializar libremente sus animales en pie en el área de frontera, pasaron a depender, por efectos de la reorientación comercial obligada, de la sucesiva intermediación de comerciantes y acopiadores. Se ha demostrado asimismo cómo estos últimos, beneficiados por la nueva coyuntura, se convirtieron en la única vía posible de acceso al mercado nacional por parte de los pequeños y medianos productores,

11 Como ejemplo más destacado de la práctica aludida, cabe mencionar la compra a fines del siglo de más de 400000 ha en el territorio nacional del Neuquén por parte de la Sociedad Comercial y Ganadera de Chile y Argentina, integrada por capitales de casas comerciales chilenas, exportadoras directas de lanas y cueros a Europa. (Este tema se encuentra desarrollado en detalle en Susana Bandieri, et al. 1995:133-152).

12 Esta hipótesis se encuentra desarrollada por Susana Bandieri en: "Mercado interno y regiones marginales: Un ajuste de periodización", (1997). 
mayoritarios en varias áreas del interior rural neuquino. De tal modo, estos grupos fueron conformando las estructuras de poder a nivel local y en su calidad de burguesía comercial habrían accedido luego al poder político provincial (Bandieri, 1991a).

\section{LAS POLÍTICAS COMERCIALES GANADERAS Y EL RÉGIMEN DE "CORDILLERA LIBRE"}

Superados los conflictos limítrofes de fines del siglo pasado, apareció una manifiesta voluntad política desde Argentina para acordar tratados de comercio con Chile, Es así como, en abril de 1908, se conformó una delegación comercial presidida por el Ingeniero Luis A. Huergo, a efecto de visitar el país trasandino y estudiar comparativamente la diversidad de productos de ambos países que pudieran servir de base para un futuro tratado comercial. Como resultado de tal gestión, se retomó el concepto de "cordillera libre", acuñado desde mediados del siglo anterior, con la intención de "[...] liberar de derechos de aduana a todos fos productos cultivados o industrializados de los dos paises, con la sola excepción de los aguardientes y vinos comunes". Esto implicaba la liberación total para "ganados, cereales y pastos" de Argentina a Chile y del "salitre, cáscara de quillay y otros productos genuinos" de Chile a la Argentina (Huergo, 1910;4).

Se consideraron ampliamente los antecedentes desde la Constitución nacional de 1853, donde se mencionaba la celebración de tratados de amistad, comercio y navegación con varios países, concretado en el caso chileno en 1856. En este acuerdo, vigente por 12 años, Chile recibía tratamiento de nación favorecida, estableciéndose el régimen đe "cordillera libre" por el cual ambos paises firmantes se comprometían a eximir de todo derecho a los productos ingresados por tierra. A pesar de que este tratado fue desconocido por Chile en 1868, por estimarse que no ofrecía compensaciones comerciales equivalentes, la importación de ganado argentino, con el solo pago de derechos de peaje, ${ }^{13}$ continuo creciendo en forma sostenida hasta 1896. En diciembre de 1897, por Ley núm. 980, el congreso chileno estableció el primer impuesto de internación al ganado

\footnotetext{
${ }^{13}$ La Ley de derecho de peaje para los animales que se trafiquen por los caminos de la cordillera, con el objeto de aplicarlo al mantenimiento de los boquetes y caminos, fue establecida en Chile el 16 de octubre de 1868. un buey o macho de matanza, pagaría 40 centavos; una vaca de matanza, 25 centavos; un caballo, asno o mula mayor de tres años, con carga o sin ella, 10 centavos; menor de tres años, 5 centavos; 2 centavos por cada lanar, cabrío o cerdo y 1 peso por cada animal con carga que vaya o venga de la Argentina (cit. en: Boletín de aduanas, s/f:175).
} 
argentino, exceptuándolo del peaje. El derecho se incrementaría anualmente hasta alcanzar su máximo sobre fines de siglo para los vacunos adultos, dejando libres de derechos la introducción de temeros menores de un año; esto último con la intención de proteger el desarrollo de la crianza chilena (Boletín de la Sociedad Nacional de Agricultura, 1909:915-916). Asimismo, se eximía de todo impuesto al ganado del país que retornara luego de pastar en campos argentinos, con lo cual se favorecía la complementación económica entre la precordillera patagónica como área de cría y los fundos cerealeros del sur chileno como área de engorde. Esta última franquicia habría permitido, de hecho, un generalizado contrabando de ganados argentinos, que no sólo pasaban como "locales" sino también "disfrazados de temeros". ${ }^{14}$ El gobiemo argentino, en respuesta, impuso un gravamen al ganado chileno que invernara en el lado oriental de la cordillera, provocando que en 1904 se eliminase la mencionada franquicia chilena, suspendiendo ese país la entrega de torna-guías para el pastaje de animales en campos argentinos (Boletín de leyes y decretos del gobierno, 1904).

Las medidas tomadas por la ley de 1897 , si bien fueron consideradas por algunos sectores en Chile como el primer hito en la historia del proteccionismo nacional, aparecen, sin embargo, como una estrategia absolutamente coyuntural y relacionada con el agravamiento de los litigios fronterizos entre ambos países sobre fines del siglo pasado y comienzos del actual. Sin duda que, en esos años, el volumen de la internación de ganado argentino a Chile era muy importante, y estas medidas de protección se hicieron sentir rápidamente. ${ }^{15}$

Sin embargo, pocos años después, volvería a modificarse la política comercial referida a la introducción de ganado argentino cuando, en 1907, el congreso chileno sancionó una ley que suprimiría por cuatro años los derechos de importación al vacuno argentino, "[...] en atención a la

\footnotetext{
14 Véase como ejemplo, las apreciaciones de Luis A. Huergo cuando analiza el hecho de que en 1902 pasaran desde Neuquén a Chile, por los caminos de Pucón, Antuco y Lonquimay, 21549 terneros, frente a 340 machos y 621 hembras (Huelgo, 1910:43).

${ }^{15}$ Dice Huergo, respecto a la significatividad del comercio de ganado argentino con destino al país trasandino durante la segunda mitad del siglo $\mathrm{xx}$ y primera década del $\mathrm{xx}$ : "La importación de ganado de la Argentina a Chile fue creciendo desde 1850; de 1889 a 1896 alcanzó un valor que varió desde 7500000 hasta 8700000 pesos moneda nacional argentina (22 peniques), descendiendo con gran rapidez en los años posteriores, aun a menos de 1500000 pesos de la misma moneda" Por su parte "[...] la exportación de bovinos fue en 1882 de 29982 animales, subió en 1889 a 83736 , en 1895 a 97417 , bajó (luego del sucesivo mayor impuesto de 1888,1889 y 1900) hasta 13888 en 1901 y subió con alternativas a 27324 en 1906 y a 34914 en 1907. Las cifras, salvo el desconocido contrabando, son elocuentes". Arriesgando una estimación para 1910 "[...] en estos últimos años no sería extran̆o que Chile hubiera importado de la Argentina más de 150000 bovinos, con un vaior de más de 15000000 de pesos chilenos" (Huelgo, 1910:76, 78).
} 
cantidad de ganado introducido en Chile clandestinamente" ${ }^{16}$ Si bien es cierto que el contrabando se realizaba en importante escala y con bastante impunidad, no pueden desconocerse otros motivos que sin duda influyeron en tal decisión, como seguramente fueron las manifestaciones de impopularidad que había provocado en Chile el impuesto con que se gravaba al ganado argentino, tema éste que serviria de detonante de los graves sucesos acaecidos en Santiago el 22 de octubre de $1905 .^{17}$ Este conflicto social, verdadero fenómeno de masas producido por la desigual distribución de la riqueza nacional, exigía cambios en la política arancelaria chilena, al considerar que protegía ciertos rubros de la producción nacional, a través de la creación de un tributo que favorecía a una minoría de hacendados y provocaba el aumento de precios de los bienes de consumo popular, en este caso, la carne.

${ }^{16}$ Ley 2060 de diciembre de 1907 , en Boletín de leyes y decretos del gobiemo (1907). Varias fuentes documentales hacen referencia a ta escasísima confiabilidad de las estadisticas para medir el comercio legal de ganado entre Argentina y Chile. Así, por ejemplo, en 1901, las proviocias del norte chileno (Antofagasta, Atacama y Coquimbo) habrian internado $70 \%$ del total del país, en tanto que el resto apenas aparece con el $30 \%$ restante, a pesar de abarcar las zonas más pobladas y de mayor consumo de Chile. Se menciona como ejemplo más evidente de fraude en la reacuadación impositiva chilena, el caso de la aduana de Lonquimay, en la provincia sureña de Cautín: "Contrabandeándose, según voz pública, tanto en Chile como en la Argentina, más de la mitad de ganado que se importa a la primera, y reduciendo a terneros más de la mitad del número que se reconoce como importado [...]" (Huergo, 1908). "Debe advertirse que la suma de 1358537 pesos oro que representa la exportación a Chile, es sólo lo que aparece en la estadistica, pudiéndose calcular en tres veces más de esa cantidad lo que se introduce en ganado de contrabando, suma de las cuales no se puede dejar constancia, porque ello es materialmente imposible. Es completamente público y notorio que lo que entra alli en ganado de contrabando supera en tres veces a lo que se consigna en la estadistica comercial argentina" (Informe de Consulado General de Chile en la República Argentina. 1908:8).

17 Nos referimos al tristemente célebre episodio de la historia social chilena acaecida en esa fecha, conocida como "semana roja", cuando el Comité Central de Impuesto al Ganado citó a las sociedades obreras y pueblo en general a participar en un desfile a realizarse simultáneamente en todas las ciudades chülenas, como manifestación pacifica de protesta para la derogación del referido impuesto, tema que se consideraba una "necesidad nacional" porque afectaba directamente a los sectores populares, La manifestación, que alcanzó en Santiago una dimensión impresionante, contó con la participación de alrededor de 30000 personas y terminó luego de cinco días en los que se sucedieron serios disturbjos y una durisima represión por parte de las autoridades, provocando detenciones, hendos y cerca de 250 muertos. Aunque los motivos de tal explosión social son mucho más complejos, el factor detonante fue el impuesto a la carne argentina, lo cual está mostrando claramente la importancia del tema en esos años. Entre las pancartas que encabezaban la manifestación, se destacaban, por ejemplo, una que mostraba a un buey aprisionado por los ganaderos y al pueblo tratando de liberarlo: en otra, aparecia un esqueleto humano -el pueblo- y a su lado un gordo personaje - el hacendado- fumando un cigarro; otra mostraba a un buey gordo sobre el cual decía "carne para los ricos", y a su lado un caballo triste y flaco con la leyenda "carne para el pueblo". Otra leyenda decía: "Abajo los monopolios. El pueblo manda que se suprima el impuesto" (Izquierdo, 1976:59). 
Esta situación motivó que se iniciaran las tramitaciones para un nuevo tratado de comercio, precedido de una serie de tres conferencias realizadas a fines del año 1905 , donde se discutieron los productos chilenos y argentinos que podrían importarse con exención o reducción de derechos. En 1907, considerando la reciente medida del congreso chileno de abolir los derechos de importación al ganado argentino, los miembros de la Delegación Comercial Argentina acordaron, por unanimidad, proponer como base del nuevo tratado de comercio la formula de "cordillera libre", liberando de derechos aduaneros a todos los productos. Finalmente, en el Acta Protocolizada, firmada en febrero de ese año (1907), se acordo la abolición del impuesto al ganado argentino por la vía del intercambio compensado con algunos productos chilenos, tales como vinos, maderas de toda especie, salitre, frutas, legumbres, verduras y mariscos conservados.

Para Argentina, el tema de la liberalización de aranceles al ganado en pie exportado a Chile resultaba ser, en la época, una medida muy significativa, ya que representaba entre 70 y $90 \%$ de las exportaciones a ese pais. De esta manera se favorecía especialmente la situación de las áreas fronterizas productoras de ganado, que trasladaban libremente sus animales a través de la cordillera para venderlos en las principales ferias ganaderas realizadas periódicamente en los centros chilenos, con las consecuencias económicas a nivel regional que ya bemos señalado. Para Chile, la provision permanente de ganados argentinos permitía abastecer su mercado interno, habituado desde antiguo a una dieta carnicera que obligaba a la importación de animales, habida cuenta del importante desplazamiento producido en la ganadería autóctona por efecto de la expansión agrícola y minera. El gobiemo de ese país usaba además, la liberación de derechos ganaderos como herramienta de presión a la hora de demandar de Argentina tratos igualitarios por intercambios compensados, particularmente con los vinos chilenos.

De hecho, el criterio de "cordillera libre" para el comercio ganadero, particularmente defendido por Argentina, logró imponerse, con algunos retrocesos, en las transacciones comerciales de esos años hasta que la primera guerra mundial marcó los primeros cambios significativos. En efecto, la Ley arancelaria 3066 del 1 de marzo de 1916, se dictó en Chile en concordancia con el discurso proteccionista que se había profundizado con el conflicto mundial. Se fijaban en ella los distintos aranceles para la internación de productos del extranjero, estableciéndose, en el caso de los animales vivos, un nuevo derecho de 16 y 10 pesos, respectivamente, para vacunos machos y bembras; 10 para caballares y mulares, 2 para ovinos y 1 para cabríos, en tanto quedaban libres de impuestos los ganados que 
fueran introducidos a Magallanes (Ley 3066 del 1 de marzo de 1916 en: Anguita, 1918:267 y ss.). Los boletines de la Sociedad de Fomento Fabril (Sofofa) de esos años y, en general, de toda la década de 1920, son muestra fiel de las presiones ejercidas desde ésta y otras corporaciones, como la Sociedad Nacional de Agricultura, para que el desarrollo de la industria chilena sea entendido como factor de defensa nacional, insistiendo en la necesidad de revisar las políticas arancelarias, incluida la de $1916,{ }^{18}$ y retornar a las medidas proteccionistas tomadas en 1897. Partidarios de eliminar la liberación impositiva, estas corporaciones entendían que el tema de la libre internación de ganados por la vía cordillerana era un factor especialmente desfavorable a la hora de lograr un desarrollo nacional autónomo. En coincidencia con esto, versiones historiográficas más modernas ubican en la misma época - primera guerra mundial y colapso de la etapa salitrera-el inicio en Chile del proceso sustitutivo de importaciones que se habría acelerado con la crisis de los años treinta. ${ }^{19}$ En respuesta a estas medidas, el gobierno argentino también gravó la exportación de animales en agosto de 1917.

En Chile, de 1919 a 1921, los aranceles aduaneros para los ganados vacunos y ovinos introducidos por la cordillera quedaron suspendidos por la Ley 3450 de 1918. En 1921, nuevamente se legisló respecto a una elevación del $50 \%$ de los derechos de internación de ganados fijados por la Ley de 1916. Sin embargo, al entenderse que el desarrollo de la ganadería nacional no permitía todavía la imposición de derechos a todos sus productos, el gobiemo tomaba sucesivas medidas de liberación, como el Decreto núm. 17 de 1924, que volvía a suspender el incremento antes mencionado, aunque sólo para el ganado argentino que se introdujese por los pasos de los Andes y San Pedro de Atacama, con el objeto de abaratar la carne en el centro y norte de ese país, que se había visto afectado por grandes sequías. También se liberaron los derechos de internación de bovinos hembras menores de tres años, aunque la medida se aplico solamente a los resguardos de los Andes en el norte y Planchón y Lonquimay en el sur. A pesar de los aranceles vigentes, los precios de las

\footnotetext{
18 'El problema económico consiste en producir. La medida más urgente para la defensa de la industria nacional es la revisión del arancel aduanero promulgado en 1916. Los derechos aduaneros han quedado muy bajos [...]" (Boletín de la Sofofa, 1918:738). Los proyectos, en orden cronológico, presentados en esos años para la revisión del arancel aduanero, son los siguientes: Proyecto Sofofa de 1918; Proyecto de la Alta Comisión de Gobierno de 1919; Proyecto elaborado por Jorhe Hörmann en 1922 en el seno de la Comisión de Hacienda de la Cámara de Diputados; Proyecto de la Sofofa de 1923, fruto de la revisión de los tres anteriores. (Boletín Sofofa, 1923).

19 Sobre el particular puede verse, de J. Gabriel Palma, "Chile 1914-1935: de economía exportadora a sustitutiva de importaciones" (1984:61-88).
} 
importaciones habian aumentado notablemente, con lo cual el gravamen protectivo quedaba en la práctica teducido. Por otra parte, la frontera seguía apareciendo como territorio de escaso control. ${ }^{20}$

Sobre la segunda mitad de la década de 1920 , el debate réspectó al establecimiento del régimen de "cordillera libre" seguía vigente. El gobierno chileno, presionado por los grupos que controlaban la comercialización y distribución del ganado argentino, insistía en mantenerlo para el intercambio de productos nacionales entre ambos países sobre la base del estudio de las compensaciones posibles. Los grupos industrialistas clamaban mayor protección, aduciendo que las reformas de comienzos de la década de 1920 no resultaban satisfactorias y que debían tomarse medidas similares a las de 1897 (Boletín de la Sofofa, 1921:80).

Finalmente, en el año 1927, el gobiemo chileno dictó la Ley 4121, fijando nuevos derechos de internación de animales vivos, en un régimen aduanero perfeccionado en 1930 con el objeto de "[...] proteger a la ganadería nacional que venía decayendo en forma grave desde hacía tiempo y hasta el extremo de hacer necesaria la importación de vacunos argentinos por un valor de 60 a 70 millones de pesos por año". ${ }^{21}$ Esta ley fijaba un impuesto importante, especialmente para vacunos. Las bembras bovinas para crianza menores de dos años, introducidas por los pasos de Uspallata, Planchón, Lonquimay y Pucón, pagarian sólo el derecho mínimo hasta el 31 de diciembre de 1930, así como las hembras de ovinos y caprinos que ingresasen por el norte del país (Boletín de leyes y decretos del gobierno, 1927:2238-2242). La Ley 4915 de diciembre de 1930, por su parte, derog6 a la anterior, fijando para vacunos, machos y hembras, un derecho de internación muy alto, de 120 pesos, "[...] que se rebajaría o alzaría en seis pesos por cada centavo que respectivamente suba o baje de 1.30 pesos el precio armónico del kilo de animal vivo en las ferias de Santiago"; y menores para otros animales, exceptuando solamente aquellos introducidos para industrialización y consumo en el territorio de Magallanes.

\footnotetext{
${ }^{20}$ Para 1924, la aduana de Lonquimay, por ejemplo, ubicada en la región que nos ocupa, reconocía como zona secundaria ocho pasos y boquetes, de los cuales habilitaba solamente dos caminos. De esa manera, una serie de sendas secundarias sin control, facilitaban el contrabando. Los animales de crianza se llevaban a veranada sin clasificación al guna, lo cual, sumado a la guía de libre tránsito, a la falta de normas estrictas en materia de marcas y a la existencia de numerosos campos limítrofes, favorecía el permanente cruce de ganados sin registro legal alguno ( $c f r$. Tiberio Pezoa P., 1930:143-144).

21 "Sobre el tratado comercial con Argentina", carta del Presidente de la Sociedad Nacional de Agricultura de Chile, Maximiliano Ibáñez, al ministro de Relaciones Exteriores de ese país, fechada en Linares el 24 de febrero de 1933, y reproducida en el Boletín de la Sociedad Nacional de Agricultura (1933:163-164).
} 
(Diario oficial 15852, diciembre 19 de 1930). Estas leyes, de escala movible, elevaban, bajaban o suprimían los derechos aduaneros, según los precios del ganado se acercaran o distanciaran del costo de la came en las ferias de Santiago. El presidente de la república fijaria quincenalmente los derechos a regir, así como la relación entre los precios medios del kilo de animal vivo en la feria y el de expendio de la carne al por mayor y menor. Con estas medidas se pretendía proteger al mercado consumidor, evitando el encarecimiento injustificado de la carne. La población ganadera chilena se elevó rápidamente y el país llegó a autoabastecerse a pesar de las condiciones de la crisis internacional. La eliminación de la fiebre aftosa en Chile también se atribuyó a los logros de esta política arancelaria. (Boletín de la Sociedad Nacional de Agricultura, 1933;164). El aumento de los aranceles se complementó en el mismo año de 1930 con un Reglamento para la internación por los caminos en las aduanas de fronteras terrestres, que demandaba a los interesados el cumplimiento de una serie de trámites legales previos a la introducción del ganado, que debía hacerse exclusivamente por los pasos habilitados, bajo el control de los carabineros, con la guía correspondiente y abonando en efectivo los derechos establecidos. ${ }^{22}$

A estas medidas del país trasandino, se sumó el adicional del $10 \%$ a las mercaderías de importación establecido por el gobierno argentino en 1931. El desenvolvimiento de la ganadería regional se agravó por la aplicación de los acuerdos de ese mismo año sobre control de cambios, a partir de los cuales comerciantes y productores ganaderos debían necesariamnte detenerse en la frontera a efecto de que se les entregara la documentación de tránsito correspondiente; es decir, debían cumplirse los requisitos impositivos antes de realizarse la operación comercial. Esto alteró sensiblemente la modalidad imperante en las áreas de frontera, donde nunca las transacciones se hacian de manera anticipada.

En junio de 1933 se firmó en Buenos Aires un nuevo tratado comercial con vigencia de tres años, renovable por otros tres, donde se establecía el tratamiento aduanero a los distintos productos internados por cada país. En esta oportunidad, los impuestos al ganado argentino se mantuvieron altos ( 68 pesos por cabeza), El Estado chileno afirmaba de esa manera su intención de mantener con producción propia las demandas de su mercado interno. De todas maneras, la internación de ganado argentino era ya considerablemente menor, asi como el conjunto del intercambio entre

20 Decreto 5196 del 9 de octubre de 1930 (Diario oficial, 17 de otubre de 1930). 
ambos países ${ }^{23}$ y los efectos de la disminución del comercio ganadero se hacían sentir en la región que nos ocupa, en coincidencia también con la crisis internacional. ${ }^{24}$

Estas medidas provocaron una gradual e importante paralizacion de las operaciones comerciales basta que, años más tarde, la situación tuvo un corte más definitivo en la década de 1940, cuando la profundización de la fase de industrialización de la economía argentina supuso para el área mayores barreras aduaneras, hecho con el cual se terminó de descomponer el mercado más específico de la producción ganadera regional.

Posteriormente, nuevas corrientes integracionistas surgidas en América Latina luego de la segunda guerra mundial, impulsaron a los respectivos gobiernos a reiniciar acuerdos económicos con los países limítrofes. Es así que se firmo, en 1953, el Tratado de Unión Económica entre Argentina y Chile, contemplando puntos tales como la posible complementación económica, los problemas de transportes, las posibilidades de una supresión arancelaria gradual, etcétera. Se retomaba asimismo, como luego veremos, el proyecto de construcción del Ferrocarril Trasandino del Sur. Por efecto de este tratado, las ventas a Chile se incrementaron $75 \%$ en 1954 con consecuencias significativas en el saldo de la balanza comercial. ${ }^{25}$ Consecuentemente, se habria producido una reacción defensiva de los productores chilenos decididos a sostener la posición referida a la necesidad de disminuir las importaciones de carne y lograr el autoabastecimiento de trigo.

En la nueva instancia histórica, el concepto de "cordillera abierta" reemplazó al de "cordillera libre" en relación directa con los cambios

\footnotetext{
${ }^{23}$ Dicen las fuentes chilenas en la década de 1930, refiriéndose a la importación de ganado vacuno de Argentina: "[...] las diferencias de las cifras entre el presente año y el anterior se deben especialmente al alza de los derechos de internación, a la crisis general del comercio y a la gran of erta de ganado en el pais" (Boletin de la Sofofa, 1930a:547). "El total de vacunos ingresados al pais por los diferentes puertos y resguardos desde el 1/01 al 30/09 ascendió a 64677 contra 122400 en la misma temporada anterior" (Boletín de la Sofofa, 1930b:842). "Las cifras más altas [refiriéndose al movimiento del comercio general entre Chile y Argentina que incluye en cuadro] cortespondieron al año 1929, y esas cifras empezaron a declinar progresivamente desde 1930 hasta el ab̉o actual" (Boletín de la Sofofa, 1936).

24 Sólo tomando groseramente las cifras consignadas en los anuarios estadísticos chilenos, pueden verse los efectos de la aludida disminución. Sobre casi 2000000 de vacunos machos, 319000 hembras y 552000 ovinos ingresados de Argentina por los pasos cordilleranos del sur en 1919, corresponden respectivamente, en 1925, 35000, 19000 y 66000 animales; en 1929: 81000,49000 y 464000 . Para 1930, las cifras han sufrido una considerable disminución: 6000 vacunos machos, 1900 hembras y 263000 ovinos. Las importantes cantidades de ovinos provienen principalmente del área de Magallanes, exenta de los impuestos fijados por la Ley de 1927. (Anuarios estadisticos de la República de Chile, Comercio Exterior, Archivo Nacional, Santiago, números varios).

${ }_{25}$ Sobre las implicaciones de este tratado, véase de Ricardo A. Rivas y Ma. Beatriz Gentile, Burguesia regional e integración con Chile. El Tratado de Unión Económica de 1853 (1989).
} 
operados en las economías regionales de ambos países, donde los resguardos sanitarios, las relaciones de precios y las características de la demanda limitaban naturalmente la posibilidad de un intercambio absolutamente libre.

El principio de "cordillera abierta" se volvió a encarar en sucesivas instancias históricas - primera mitad de la década de 1970 y luego de 1983 en Argentina - siempre en coincidencia con las reaperturas democráticas de ambos países y la marcha de los respectivos procesos políticos nacionales. El alcance de tal concepto aparecía disminuido con respecto al pasado, por cuanto los diferentes desarrollos de las economías nacionales exigían otras consideraciones. Sin duda que, desde lo comercial, el intercambio potencial se había modificado con los años, superando la cuestión de las meras restricciones arancelarias para derivar en problemáticas vinculadas con resguardos sanitarios o demandas relativas, por ejemplo. Sin embargo, la posibilidad de una mayor integración sigui 6 y sigue viéndose como alternativa posible, abarcando nuevos rubros comerciales y otras formas de intercambio relacionadas con distintos recursos naturales, tecnológicos, turísticos, etcétera.

Más recientemente, según adelantáramos en la introducción, parecen haberse producido -en el marco del Mercosur-avances significativos en la discusión sobre el tema de la integración comercial argentino-chilena aunque, simultáneamente, las tratativas limítrofes derivadas, vinculadas con el área de los hielos continentales del sur, hayan generado no pocas expresiones de oposición de ambos lados de la cordillera.

En fin, como dijéramos al comienzo, tras el difícil tema de la integración binacional se mueven muchos y variados intereses que vuelven difícil arriesgar pronósticos. Entretanto, desde las provincias del norte de la Patagonia argentina, la relación con Chile y los mercados del Pacífico sigue viéndose como alternativa posible de un nuevo modelo de desarrollo regional, sustentado ahora por las respectivas burguesías provinciales.

\section{LA INTEGRACIÓN COMO PROYECTO POLÍTICO REGIONAL}

Según venimos diciendo, y por encima de los acuerdos comerciales, el tema de la integración entre Argentina y Chile es una historia compleja, con avances y retrocesos, acuerdos y desacuerdos. Tiene que ver con el difícil tema de los límites fronterizos y con las condiciones internas de ambas naciones y sus consecuentes líneas de política exterior.

Desde la pespectiva norpatagónica, la cuestión de la integración fronteriza ha estado tradicionalmente vinculada con los intereses de los sectores dominantes a nivel regional, siempre marginales en lo nacional y, por 
ende, interesados en la búsqueda de altemativas posibles al modelo de desarrollo centrado en la economía pampeana y el puerto de Buenos Aires.

Para el territorio del Neuquén, por su posición mediterránea, bastante ajena al comercio atlántico en sus primeras etapas históricas, la relación con Chile fue siempre importante y, de hecho, práctica continua y cotidiana. Según hemos señalado, la investigación ha permitido visualizar desde la historia tal relación, donde en un claro modelo de economías complementarias entre un área de ganaderia extensiva orientada a la cría -Neuquén-y otra de consumo y transformación - Chile-, el permanente intercambio fronterizo permitió que la región se transformara, durante la etapa de mayores franquicias comerciales (1880-1927), en hinterland de los centros urbanos de las provincias chilenas meridionales $\mathrm{y}$ de sus principales puertos sobre el Pacífico sur.

La práctica integracionista ha sido, por ende, para los locales, una alternativa posible, particularmente en el ámbito rural cordillerano, durante buena parte de su etapa de territorio nacional (1884-1955), sin que por ello alcanzase nunca, en ese periodo, la fuerza y coherencia necesarias de un planteo político capaz de influenciar considerablemente sobre el poder nacional en ejercicio del gobierno territoriano, siempre desconfiado de los intereses expansionistas chilenos. Cabe agregar aquí la manifiesta preocupación de los sucesivos gobernadores de la etapa por cortar, sin éxito, las prácticas sociales vigentes entre las poblaciones del interior rural, como aquélla generalizada de casarse y anotar el nacimiento de sus hijos en Chile, por ejemplo. Esto no era otra cosa que una expresión más de la integración que, de hecho, existía alrededor del área cordillerana, así como de la persistencia de una forma de organización social y territorial que ya hemos descrito. Aún más, hasta avanzadas las dos primeras décadas de este siglo, la provisión de bienes de consumo desde Chile fue una constante, así como también lo fue el uso de la moneda de ese origen muchas veces como el medio de pago circulante más generalizado, sobre todo en el área rural del noroeste neuquino. Todas estas prácticas se verían seriamente afectadas por la aplicacion de las medidas arancelarias y el corte de las franquicias comerciales ya señaladas.

A partir de la provincialización del territorio en la segunda mitad de la década de 1950, se constituyó un partido provincial de fuerte discurso federalista (Movimiento Popular Neuquino), que más recientemente ha hecho de la cuestión de la integración con Chile una de sus banderas fundamentales. En este caso, los sucesivos triunfos electorales han permitido al partido provincial una posición de mayor peso en la decisión política, particularmente en los últimos años donde se ha vuelto más evidente el agotamiento de un modelo de desarrollo provincial basado en 
la obtención de regalías nacionales por la explotación de sus recursos energéticos. Esto plantea la necesidad más reciente de nuevas vías alternativas de colocación de la producción regional, particularmente de rocas de aplicación, minerales diversos y combustibles como petróleo y gas. En tal sentido, resultan significativos los avances respecto al fomento de las comunicaciones aéreas y terrestres, así como la realización de estudios de factibilidad de futuros acuerdos comerciales con el país trasandino.

Los ganaderos del noroeste neuquino, por su parte, siguen insistiendo en la necesidad de reabrir el comercio de ganado con Chile como única alternativa válida de reactivación económica del área, una de las más afectadas por la crisis de la actividad que se profundizara en los años treinta. Para esto, consideran necesario que Chile acepte la validez operativa de la barrera sanitaria del río Colorado y reconozca a la región como zona libre de aftosa. ${ }^{26}$

Para la provincia de Río Negro, particularmente para la zona de agricultura intensiva del Alto Valle del Río Negro, productora de peras y manzanas para exportación, el interés por la integración comercial con Chile se vincula con la necesidad de una mayor presencia en los mercados del Pacífico aunque, de hecho, esto genera en la actualidad una seria situación de competitividad para el mercado chileno productor de frutas que ha superado al argentino en calidad y tecnología.

Desde la perspectiva histórica, el trabajo de Rivas y Gentile (1989) muestra cómo los intereses norpatagónicos tuvieron en las décadas de 1940 y 1950 su representación más significativa en la abortada estrategia de desarrollo puesta en marcha desde el sur bonaerense por la burguesía de la ciudad-puerto de Bahía Blanca, a través de la revitalización del proyecto del Trasandino del Sur. Este ferrocarril, planeado desde el siglo pasado, contó en esa especial coyuntura histórica con el apoyo de la gestión peronista en el Estado nacional.

La idea de concretar la realización de un ferrocarril trasandino por el sur no ha perdido vigencia. Aún más, ha reaparecido sistemáticamente toda vez que las instancias históricas permitieron que el tema de la integración con Chile ocupara lugares de privilegio. Desde su proyección inicial, la construcción de esta vía férrea fue considerada, primero, como factor de consolidación y defensa territorial ante la conflictiva situación limítrofe con Chile, y solucionada la coyuntura estratégico-militar sobre fines de siglo, como alternativa posible de las regiones marginales frente al modelo vigente de desarrollo agroexportador centrado en la llanura pampeana.

\footnotetext{
${ }^{26}$ Un buen ejemplo de la antigùedad de tales reclamos, puede verse en Diario Rio Negro (25 de agosto de 1982:12 y 26 de agosto de 1982:11).
} 


\section{EL TRASANDINO DEL SUR}

La idea de unir Argentina y Chile mediante un ferrocarril, habría surgido cuando el ingeniero Juan Ignacio Alsina, comisionado por el gobierno nacional, realizó una exploración en el territorio del Neuquén. A mediados de 1885, durante el gobiemo de José E. Uriburu, el ministro Benjamín Zorrilla manifestó al presidente de la Comisión Local del Ferrocarril Sud, ingeniero Guillermo White, la intención de extender la línea desde Bahía Blanca hasta la frontera, iniciándose las tareas en 1896 (ver Moresco, 1952 y 1953). La posibilidad de un enfrentamiento armado con Chile exigía un medio de transporte rápido de hombres y pertrechos militares. Sólo tres años después, en 1899, se inauguraba el tramo de $550 \mathrm{~km}$ hasta la confluencia de los ríos Neuquén y Limay, en el vértice más oriental del territorio del Neuquén. Habrian de transcurrír catorce años más para que en 1913 se inaugurara el tramo de $187 \mathrm{~km}$ hasta Zapala, extremo actual de la línea, faltando solamente $150 \mathrm{~km}$ para alcanzar la frontera.

Aduciendo diversos motivos, seguramente vinculados con la escasa rentabilidad potencial de la línea frente a la concesion de otros tendidos, la empresa del Ferrocarril Sud fue postergando la concreción del tramo faltante hasta que finalmente, en 1917, aceptó la caducidad de las concesiones pendientes suspendiendo su compromiso con el Estado nacional. Posteriormente, luego del rechazo por el senado argentino del convenio Barros Jarpa-Noel en 1922, se frustró nuevamente el acuerdo alcanzado entre Chile y Argentina para realizar simultáneamente la construcción faltante del trasandino en un término de tres años.

El proyecto del Trasandino del Sur sería retomado, según vimos, en la segunda mitad de la década de 1940 y en distintas circunstancias históricas hasta la actualidad. En la particular instancia de la segunda guerra mundial, el entonces Territorio Nacional del Neuquén, vinculado desde antiguo con la demanda de ganado por parte de los centros urbanos chilenos, podía obtener la ventaja de maximizar el intercambio comercial aprovechando las franquicias existentes entre ambos países y las especiales condiciones fisiográficas que bacían de la cordillera de los Andes, a esta latitud, una vía de fácil acceso y permanentes contactos socioeconómicos. Pero los intereses ganaderos del área cordillerana neuquina sólo llegaron a constituir expresiones locales aisladas sin mayor proyeccion nacional. Frente a ellos, dicen Rivas y Gentile (1989:3), la burguesía bahiense logró estructurar un proyecto de mayor peso político propiciando la conexión bioceánica por el norte de la Patagonia, constituyendo una Comisión Pro Ferrocarril Trasandino del Sur, liderada por la Corporación del Comercio y la Industria de Bahía Blanca, y presidida por el ingeniero Domingo 
Pronsato, que realizaría en esos años una intensa actividad proselitista. ${ }^{27}$ Todo esto, con la pretensión de liderar el desarrollo de una nueva región en el sur del país que permitiera enfrentarse al tradicional dominio del puerto de Buenos Aires. El retomado proyecto del Trasandino del Sur incluía terminales sobre el Atlántico - puertos de ingeniero White y Galván en Bahía Blanca - y sobre el Pacífico - Talcahuano en Chile(ver figura 1). Según Ragno y Gentile, en una idea que compartimos, este proyecto no babría buscado modificar la orientación atlántica del comercio, sino tan sólo generar otros circuitos de intercambio que ampliaran la actividad productiva e hicieran de la ciudad de Bahía Blanca el nuevo centro del desarrollo regional (Ragno y Gentile, 1992:190).

El proyecto del Trasandino del Sur adquiriría así, una dimensión particular tras el modelo de desarrollo generado por los grupos de poder representativos del área sudoeste de la provincia de Buenos Aires, no sin despertar serios resquemores en los territorios patagónicos por el pretendido liderazgo bahiense. Sin embargo, los esfuerzos de la entonces conformada Comisión Pro Ferrocarril Trasandino del Sur y los avances surgidos de la firma del Tratado de Unión Económica entre Chile y Argentina en 1953, se vieron frustrados por una nueva interrupción del proceso democrático en Argentina con el golpe militar del año 1955 que derrocó al gobierno peronista.

La idea de vincularse con Chile a través del ferrocarril siguió vigente durante la década de 1960, aunque muy tímidamente expresada en proyectos fallidos presentados al Congreso Nacional. Sín duda que la visión geopolítica de los gobiemos militares influyó en ello, por lo que, consecuentemente con las nuevas condiciones políticas y la ideología nacionalista imperante, la cordillera de los Andes pasó a ser considerada nuevamente una barrera aislacionista.

En 1971, el tema del intercambio comercial se retomó más enérgicamente a partir de la contratación por parte del Consejo Federal de Inversiones (CFI) de un estudio sobre las posibilidades de intercambio de la provincia del Neuquén y el Alto Valle del Río Negro con Chile y los países del Pacífico. El informe resultante contiene estadísticas de importación y exportación de los productos con posibilidades de intercambio,

${ }^{27}$ Esta comisión mantendría permanentes reuniones con las fuerzas vivas de las más importantes ciudades del norte patagónico, realizando incluso un Congreso Trasandino en la crudad de Bahía Blanca en los meses de junio y julio de 1957. El proyecto llegó a reunir técnicos argentinos y chilenos para el estudio del trazado internacional y tuvo en la época una significativa cobertura de prensa, particularmente por parte del tradicional y poderoso diario La nueva provincia, fiel expresión de los intereses de los sectores dominantes bahienses (ejemplo de ello es la abundante cantidad de artículos publicados en ese medio sobre el tema durante los años 1957 y 1958). 


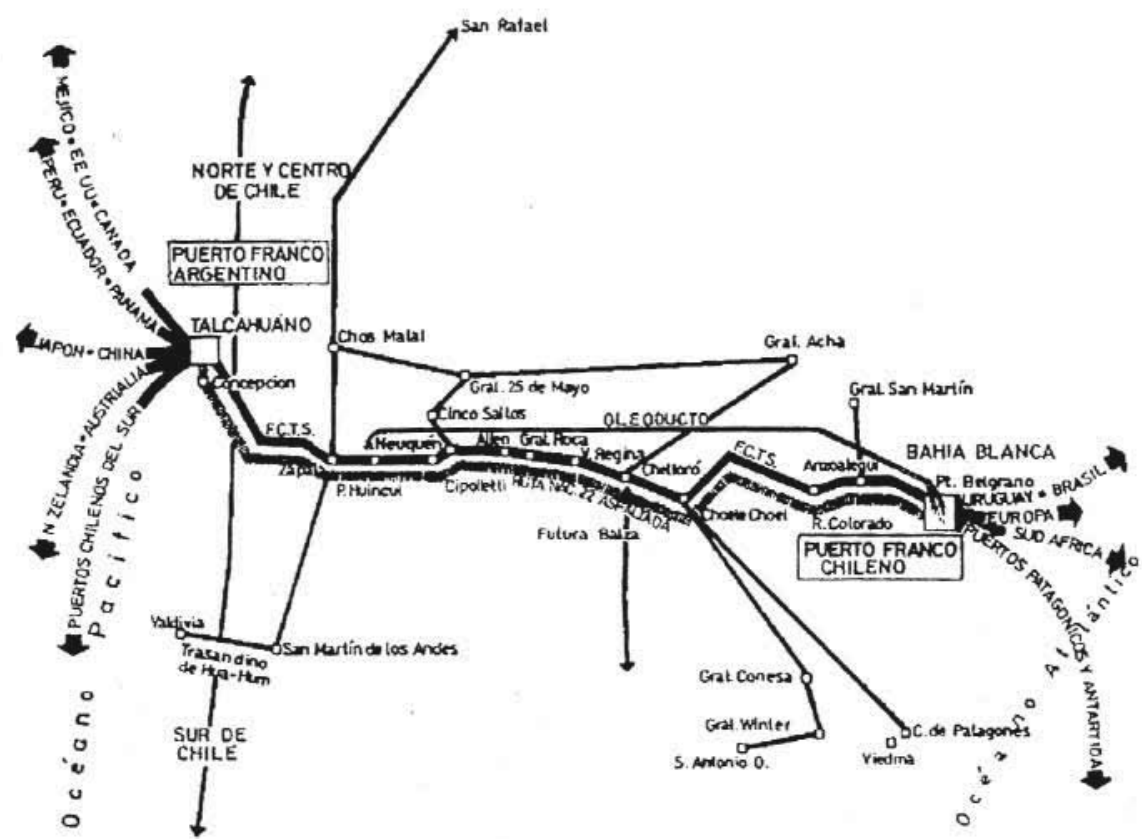

Figura 1. Propuesta de trazado del Ferrocarril Trasandino del Sur, proyecto Comisión Pro Trasandino del Sur, Bahía Blanca, 1957.

FUENTE: Reproducción del original elaborado por el ingeniero Domingo Pronsato, presidente de la Comisión Regional Pro Trasandino del Sur, publicado en el diario La nueva provincia, Bahía Blanca, julio 3 de 1957. 
así como extensas referencias sobre aranceles, volúmenes de producción, perspectivas en el mediano y largo plazo y condiciones de transporte de cargas en la cordillera. El estudio concluye señalando las dos dificultades más graves con que tropieza a esa fecha el intercambio entre ambas regiones: las elevadas barreras arancelarias y no arancelarias vigentes en ambos países, y la falta de medios adecuados de comunicación terrestre. Propone, en consecuencia, solucionar tales dificultades como requisito previo indispensable al proyecto de acuerdo comercial que incluye (Consejo Federal de Inversiones, 1974).

La segunda mitad de la década de los setenta volví́ a mostrar, en concordancia con la nueva interrupción violenta del gobierno democrático en Argentina y con la gravedad que alcanzaron los conflictos limitrofes en el área del Beagle, la cesación de las preocupaciones integracionistas que serían retomadas recién en la década de los ochenta a partir de la reapertura de las relaciones diplomáticas entre ambos países. Se firmaron así, en 1984, un Tratado de Paz y Amistad y un Acta de Entendimiento que derivaron en la creación del Comité Empresarial Argentino-Chileno.

Más recientemente, en 1990, el mismo Consejo Federal de Inversiones realiz6, a pedido de las provincias de Río Negro y Neuquén, un "Estudio de prefactibilidad económico-financiera del Ferrocarril Trasandino del Sur, conexión bioceánica", utilizando toda la información de base existente, con la finalidad de determinar la conveniencia de profundizar el proyecto. Tal estudio incluyó el análisis de las posibilidades de comercialización de los productos que componen la demanda global de transportes del área de influencia del proyecto (ver figura 2), de la estructura de precios de mercado y de los fletes que pudieran corresponder con los productos comercializables. La evaluación financiera descubrió una rentabilidad importante de acuerdo con la tasa interna de retorno. Sin embargo, el empresariado chileno pareció en esos momentos desinteresado en la concreción del proyecto, seguramente por el riesgo que implicaba la competencia que de hecho ofrecería la producción argentina a la chilena en los mercados del Pacífico, particularmente en lo que se refiere a los productos agrícolas.

En esa nueva coyuntura histórica, el proyecto del trasandino contemplaba, hacia el oeste, el trazado del ramal entre Zapala (Neuquén) y Lonquimay (Chile) y, hacia el este, el tramo entre Choele Choel y San Antonio Este (Río Negro). Si bien abarcaba indirectamente al puerto de Bahia Blanca, se proyectaba en función de incorporar los puertos rionegrinos a la conexión bioceánica. Esto último constituiría una mejora sustancial en la conexión del área atlántića rionegrina con el Alto Valle, Neuquén y el complejo portuario de Concepción-Talcahuano en Chile. 


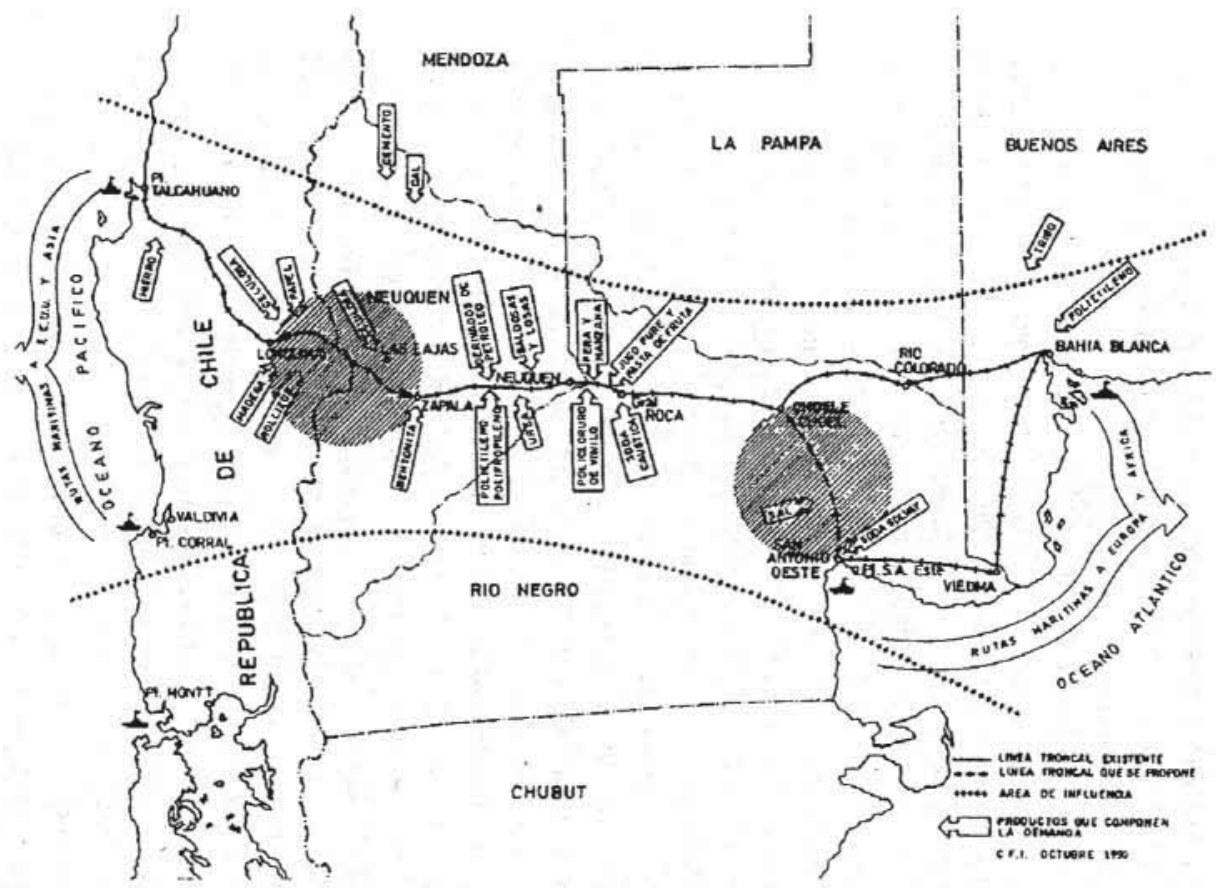

Figura 2. Proyecto de trazado del Ferrocarril Trasandino y conexión bioceánica en el sur, estudio cFI, 1990. FUENTE: Consejo Federal de Inversiones (CFI), "Estudio de prefactibilidad económico-financiera del Ferrocarril Trasandino del Sur, conexión bioceánica", reproducido en Diario Río Negro del 3 de febrero de 1991, pp. 4-5. 


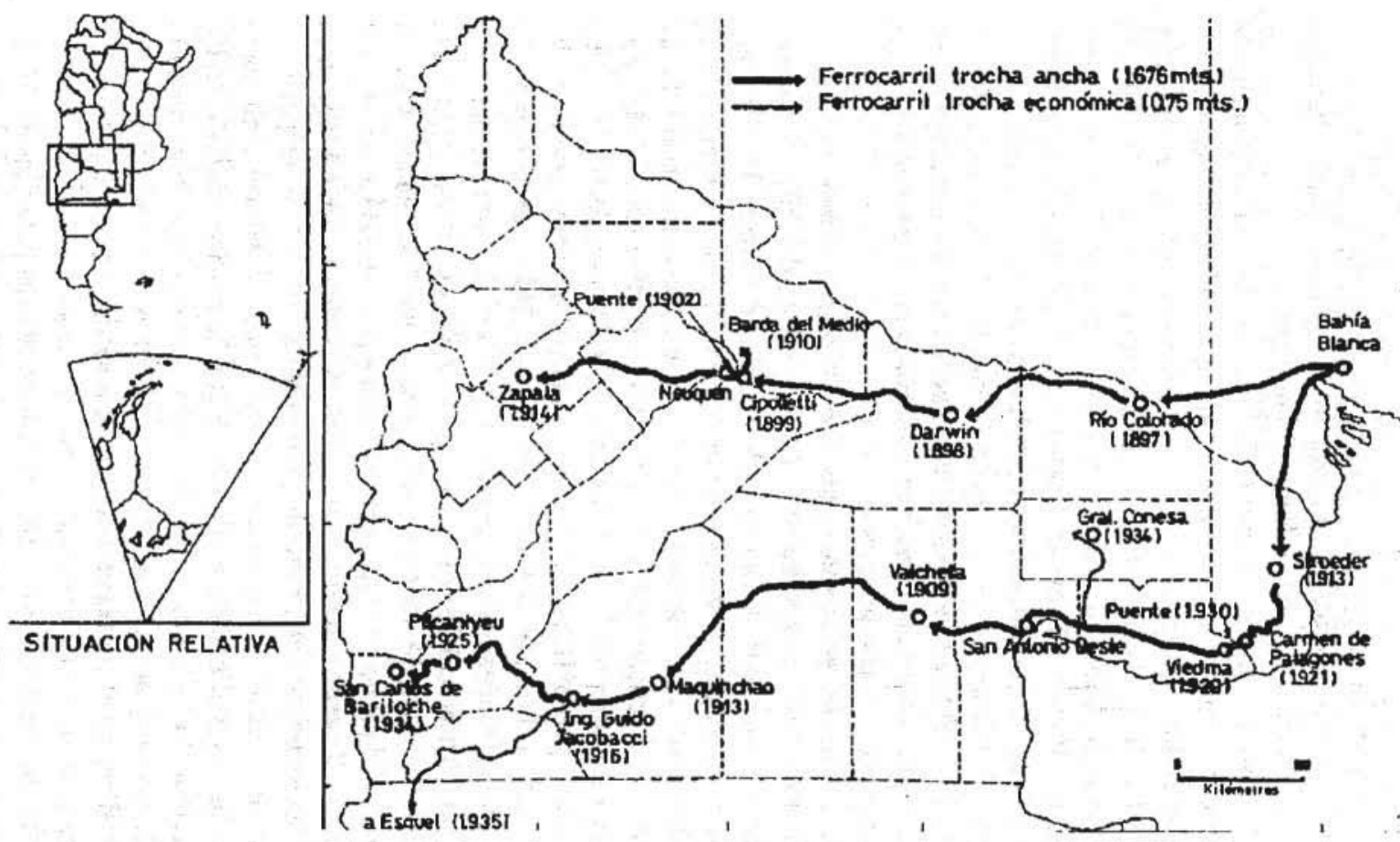

Figura 3. Mapa del norte de la Patagonia argentina: Situación relativa y trazo ferroviario actual. FUENTE: César A. Vapñarsky (1983:83). 
Puede interpretarse que este nuevo proyecto significaba, además, otra expresión regional altemativa a la tradicional y fallida pretensión bahiense de liderar con exclusividad el desarrollo regional.

Al fracaso de todos estos proyectos surgidos desde el sur bonaerense o desde la norpatagonia misma, cabe agregar también el interés de los grupos de poder económico a nivel nacional por consolidar sus mercados sobre el Pacífico, concretado en la privatización en marzo de 1993 del ramal de cargas Bahía Blanca-Zapala del ex Ferrocarril Sud (luego Gral. Roca y ahora Ferrosur Roca) adquirido por el grupo Fortabat-Loma Negra, propietario de las más importantes cementeras del país - incluida una en la propia ciudad neuquina de Zapala-, con la manifiesta intención de extender hasta el territorio chileno la punta de rieles ubicada actualmente en esa ciudad, consolidando así, su presencia en el país trasandino y en los mercados de su área de influencia.

El tema quedó pendiente hasta que la necesidad más reciente de establecer un posible corredor de cargas al servicio del tráfico comercial del Mercosur, hizo cobrar un renovado impulso al proyecto. En este caso, ya no se trata solamente de unir Argentina y Chile, sino de establecer un mega emprendimiento de carácter global, que combine transporte fluvial y terrestre desde el principal polo industrial de Brasil, en la ciudad de San Pablo, hasta la importante plaza marítima de Talcabuano sobre el Pacífico sur. Desde el puerto fluvial de Rosario, en la provincia argentina de Santa $\mathrm{Fe}$, se iniciaría el transporte ferroviario aprovechando el actual trazado del Ferroexpreso Pampeano (viejo Ferrocarril Francés) hasta Bahía Blanca, y utilizando las vías del Ferrosur Roca para el traslado de las cargas hasta Zapala, la frontera Neuquén-Chile y, finalmente, Talcahuano. Para la concreción del proyecto, quedarían solamente por cubrir el tendido de vías férreas en $150 \mathrm{~km}$ de recorrido en territorio neuquino, mejorando algo más de $200 \mathrm{~km}$ de trazado en territorio chileno hasta la costa. ${ }^{28} \mathrm{Al}$ respecto, se encuentran avanzados nuevos estudios de traza, factibilidad y mercado para medir la viabilidad del emprendimiento. La provincia de Río Negro, en el norte de la Patagonia argentina, sigue insistiendo por su parte en la ineludible necesidad regional de concretar el ramal Choele Choel-San Antonio Este, sin el cual el proyecto del trasandino pierde sentido para los intereses provinciales (Diario Río Negro, 27 de abril de 1996:26-27).

En fin, la cuestión sigue abierta. Sólo la marcha futura de los acontecimientos, producto de las decisiones políticas y económicas de los

\footnotetext{
${ }^{28}$ La prensa regional hace permanentes menciones al respecto (Diario Río Negro, 20 de abril de 1996:17; 26 de abril de 1996:26; 30 de abril de 1996:11; entre otros).
} 
grupos de poder involucrados, permitirá descubrir si la integración entre ambos países, que fuera práctica histórica de larga duración en la sociedad regional, puede hoy concretarse en el marco de la nuevas situaciones nacionales e intemacionales vigentes.

\section{BIBLIOGRAFIA}

AA.VV. Asociación de Historiadores Chilenos (U.K.). 1982, Nueva historia. Revista de historia de Chile, año 2, núm. 5, junio-septiembre, Londres.

ANGUITA, R. 1918. Leyes promulgadas en Chile: Sup. 1913-1918, vol.5, Imprenta Barcelona, Santiago de Chile.

BANDIERI, Susana, 1991a. "Frontera comercial, crisis ganadera y despoblamiento rural. Una aproximación al estudio del origen de la burguesía tradicional neuquina", en: Desarrollo económico, Revista de ciencias sociales, vol. 31, núm. 122, Buenos Aires, Instituto de Desarrollo Económico y Social, julio-septiembre.

- 1991b. "La cordillera de los Andes en el norte de la Patagonia o la frontera argentino-chilena como espacio social. Un estudio de caso", en Estudios fronterizos, revista del Instituto de Investigaciones Sociales, núm. 22, mayo-agosto de 1990, Universidad Autónoma de Baja California, México.

- 1995. "Historia regional y relaciones fronterizas en los Andes meridionales", en Siglo XXI. Cuadernos de historia, año IV, núm. 12, mayo-agosto, Universidad Autónoma de Nuevo León, México.

- 1997. "Mercado interno y regiones marginales: Un ajuste de periodización", en Jorge Pinto Rodríguez (compilador). Araucanía y Pampas. Un mundo fronterizo en América, Temuco, Chile, edic. Universidad de la Frontera.

BANDIERI, Susana, et. al. 1995. 'Los propietarios de la nueva frontera: Tenencia de la tierra y estructuras de poder en el área andina de Neuquén", en: Revista de historia, núm.5, departamento de Historia de la Facultad de Humanidades, Universidad Nacional del Comahué, Neuquén.

Boletín de aduanas. s/f. vol. xxv, núm. 407, Santiago, Chile,

Boletín de la Sociedad Nacional de Agricultura.1909. Vol. xxx, núm. 51, 18 de diciembre, Santiago de Chile.

- 1933. "Sobre el tratado comercial con Argentina".

Boletín de la Sofofa. 1918. Año XXXX, núm. 11, noviembre. 
- 1921. Año XXXXIII, núm. 2, febrero.

- 1923. Año XI, núm. 9, septiembre.

- 1930a. Año XIVII, núm. 8, agosto.

- 1930b.Año xı VII, núm. 11, noviembre.

- 1936. Año LiII, núm. 4, abril.

Boletín de leyes y decretos del gobierno. 1904. Publicación oficial, vol, 83, libro LXXV, Santiago de Chile.

- 1907. Libro LXXvil, vol. 89, Santiago de Chile.

- 1927. Libro XCVı, Dirección General Talleres Fiscales de Prisiones, abril-junio, Santiago de Chile.

Consejo Federal de Inversiones. 1974. Análisis del intercambio entre la provincia del Neuquén y zona del Alto Valle del Río Negro con Chile y países del Pacífico, resumen del informe, Serie Técnica núm. 27, edición del CFI, Buenos Aires.

HUERGO, Luis A. 1908. "Informe de la Delegación Comercial Argentina acerca del tratado de comercio con Chile", julio 18, en: Boletín de la Sofofa (Sociedad de Fomento Fabril), 1911, año XXXII, núm. 6 , Litografía Universo, Chile.

- 1910. Conversación. Exponiendo y aclarando los puntos principales de los informes producidos por los miembros de la Delegación Comercial enviada a Chile por el gobierno argentino en abril de 1908, Buenos Aires, Imprenta y Casa Editora de Coni Hnos.

Informe del Consulado General de Chile en la República Argentina. 1908. Ministerio de Relaciones Exteriores, Inf. Consulares, Santiago.

Informes generales de la Comisión Inspectora de Neuquén. 1921-1922. Comisión dirigida por el capitán de fragata, Ramón Castro, Ministerio de Agricultura, Dirección de Tierras, tomo XIX.

IZQUIERDO Fernández, Gonzalo. 1976. "Octubre de 1905. Un episodio en la historia social chilena", en Historia, núm. 13, Instituto de Historia, Pontificia Universidad Católica de Chile, Santiago de Chile.

LAURÍN, Alicia. 1994. "Del área de frontera a la región fronteriza. El caso de la provincia de Neuquén", tesis de magister, Universidad de la Frontera, Temuco, Chile, inédita.

MORESCO, Enrique. 1952. "El trasandino del Sur por Neuquén", conferencia pronunciada el 11 de noviembre de 1952 por invitación de la municipalidad de la ciudad de Bahía Blanca, en colaboración con la Comisión Pro Ferrocarril Trasandino del Sur de la misma ciudad, publicada en Revista de la Camara Chileno-Argentina de Comercio. Buenos Aires, Argentina, diciembre. 
- 1953. "Pequeña historia neuquina y del Ferrocarril Trasandino del Sur", en Revista de la Cámara Chileno-Argentina de Comercio, Buenos Aires, Argentina, mayo-junio.

OLASCOAGA, M.J. 1974. Estudio topográfico de La Pampa y Río Negro, Eudeba, Buenos Aires, Argentina.

PALMA, J. Gabriel. 1984. "Chile 1914-1935; de economía exportadora a sustitutiva de importaciones", en Colección estudios CIEPLAN, núm. 12 , estudio núm. 81 , marzo.

PEZOA P., Tiberio. 1930. “Aduanas de fronteras", en Boletín de aduanas, Organo de la Superintendencia de Aduana de la República de Chile, año XXVI, febrero.

RAGNO, Ma. Rosa y Ma. Beatriz Gentile. 1992. "Hacia una estrategia de integración regional: El Ferrocarril Trasandino del Sur (18901990)", en Estudios sociales, revista universitaria, semestral, año 2, núm. 2, Rosario, UNL, primer semestre.

RIVAS, Ricardo A. y Ma. Beatriz Gentile. 1989. Burguesía regional e integración con Chile. El Tratado de Unión Económica de 1853, Universidad Nacional del Comahué, policopiado.

VAPÑARSKY, César A. 1983. Pueblos de norte de la patagonia (18791957), Gral. Roca, Río Negro, Bd. de la Patagonia.

VARELA, Gladys y Ana María Bizet. 1993. "Entre guerras, alianzas, arreos y caravanas: los indios del Neuquén en la etapa colonial", en S. Baindieri, O. Favaro y M. Morinelli. Historia de Neuquén. Plus Ultra, Buenos Aires, Argentina.

VILLALOBOS, Sergio y Jorge Pinto Rodríguez (compiladores). 1985. Araucania. Temas de historia fronteriza, Temuco, Chile, Ed. de la Universidad de la Frontera.

\section{Hemerografía}

ÁBALO, Carlos. "La difícil relación de Chile con el Mercosur", Diario Río Negro, Gral. Roca, Río Negro, Argentina, 19 de mayo de 1996.

Diario Rio Negro. 25 de agosto de 1982, p. 12.

Diario Río Negro. 26 de agosto de 1982, p. 11.

Diario Río Negro. 3 de febrero de 1991, pp. 4-5.

Diario Río Negro. 11 de noviembre de 1993.

Diario Río Negro. 20 de abril de 1996, p. 17.

Diario Río Negro. 26 de abril de 1996, p. 26.

Diario Río Negro. 27 de abril de 1996, p. 26-27.

Diario Río Negro. 30 de abril de 1996, p. 11.

Diario Río Negro. 7 de mayo de 1996. 